\title{
ERKI/II Regulation by the Muscarinic Acetylcholine Receptors in Neurons
}

\author{
Kobi Rosenblum, ${ }^{1}$ Marie Futter, ${ }^{2}$ Matthew Jones, ${ }^{1}$ E. C. Hulme, ${ }^{2}$ and T. V. P. Bliss ${ }^{1}$ \\ Divisions of ${ }^{1}$ Neurophysiology and ${ }^{2}$ Physical Biochemistry, National Institute for Medical Research, Mill Hill, London NW7 \\ 1 AA, United Kingdom
}

\begin{abstract}
Muscarinic acetylcholine receptors (mAChRs) are known to be involved in learning and memory, but the molecular basis of their involvement is not well understood. The availability of new and specific biochemical tools has revealed a crucial role for the mitogen-activated protein kinase (MAPK) family in learning and memory. Here, we examine the link between mAChRs and MAPK in neurons. Using the MAPK kinase (MEK)-specific inhibitor PD98059, we first demonstrate a necessary role for active ERKI/II in long-term potentiation in vivo. Using phospho-specific antibodies that recognize the activated form of $\mathrm{ERKI} / \mathrm{II}$, we find that the level of ERKI/II activation in brain is regulated by $\mathrm{mAChRs}$. Carbachol, a muscarinic agonist, induces prolonged activation of ERKI/II, without effect on the
\end{abstract}

Cholinergic transmission at the muscarinic acetylcholine receptor (mAChR) has been implicated in learning and memory in humans and other mammals (Blokland, 1995). The cholinergic innervation of the cerebral cortex and the hippocampus originates primarily from the cholinergic basal nuclear complex (Mesulam, 1996). Lesions of these basal forebrain neurons have been reported to result in impairment in memory, learning, and attention, whereas cholinergic agonists facilitate learning and memory (Jerusalinsky et al., 1997).

The mAChR family consists of five heterogeneous mAChR subtypes, differentially expressed in the brain. These receptors transduce their signal by coupling to G-proteins (Wess, 1993). In neurons, activation of mAChRs can induce elevation of intracellular $\mathrm{Ca}^{2+}$ and stimulate kinase activation, as well as increasing phosphoinositide turnover (Felder, 1995). It has been shown recently that, in different cell lines, expression of mAChRs can induce proliferation by activating the extracellular signalregulated kinase (ERK) pathway (Gutkind, 1998). Multiple signal transduction pathways may mediate ERK activation by mAChRs, and there are conflicting results, probably attributed to the different cell lines used (Sugden and Clerk, 1997; Gutkind, 1998). ERK activation is both necessary for and correlated with several forms of synaptic plasticity (for review, see Orban et al., 1999), including long-term potentiation (LTP), the major cellular model of learning and memory (Bliss and Collingridge, 1993), in a rat

\footnotetext{
Received July 6, 1999; revised Oct. 27, 1999; accepted Nov. 28, 1999.

We thank Drs. Carol Curtis, Alan Fine, and Paul Skehel for useful discussion, Dr. Victor Tybulewicz for the fyn knock-out mice, and Luca Raimondi for his invaluable help in producing the primary cultures.

Drs. Rosenblum and Futter contributed equally to this work.

Correspondence should be addressed to Kobi Rosenblum, Division of Neurophysiology, National Institute for Medical Research, The Ridgeway, Mill Hill, London NW7 1AA, UK. E-mail: krosenb@nimr.mrc.ac.uk.

Copyright (C) 2000 Society for Neuroscience 0270-6474/00/200977-09 $\$ 15.00 / 0$
}

related kinase SAPK/JNK (stress-activated protein kinase/cJun $\mathrm{N}$-terminal protein kinase) in primary cortical cultures. ERKI/II activation is Src-dependent and partially phosphoinositide-3 kinase- and $\mathrm{Ca}^{2+}$-dependent but is PKCindependent. M1-M4 mAChR subtypes expressed in COS-7 cells can all induce ERKI/II activation using a signal transduction pathway similar to that operating in neurons. The nature of the signal transduction suggests that ERKI/II can serve as a convergence site for mAChR activation and other neurotransmitter receptors.

Key words: MAChR; extracellular regulated kinase; MAPK; neurons; COS-7; LTP; signal transduction hippocampal slice preparation (English and Sweatt, 1997). LTP in the cortex and the hippocampus is modulated by mAChRs (Jerusalinsky et al., 1997), and we have found recently that atropine attenuates cortical LTP in vivo (Jones et al., 1999).

To examine the extent to which mAChRs exert their effect on the mature brain via the modulation of ERKI/II activity, we have investigated the activation of ERKI/II by mAChRs in neuronal tissue. We have used different levels of analysis, ranging from the intact brain to primary cortical cell cultures, and a model system consisting of COS-7 cells expressing the different mAChR subtypes, to gain insight into the signal transduction linkages involved in ERKI/II activation and its physiological significance. We report here that ERKI/II activation is necessary for the expression of LTP in vivo in the dentate gyrus (DG) of the hippocampus. ERKI/II activity is modulated by mAChRs in the neocortex and hippocampus in vivo, in hippocampal slices, and in primary cortical neurons. Low doses of the muscarinic agonist carbachol can induce prolonged activation of ERKI/II but not another member of the mitogen-activated protein kinase (MAPK) family, stress-activated protein kinase/c-Jun N-terminal protein kinase (SAPK/JNK), in primary cortical neurons and in COS-7 cells expressing the different mAChRs. ERKI/II activation is independent of protein kinase C (PKC) but is blocked by inhibitors of the Src protein tyrosine kinase and is attenuated by phosphoinositide- 3 kinase $\left(\mathrm{PI}_{3} \mathrm{~K}\right)$ inhibitors and $\mathrm{Ca}^{2+}$ chelators. The M1-M4 mAChR subtypes can all induce ERKI/II activation when expressed in COS-7 cells and share a similar signaling pathway dependency with the neurons. Our results demonstrating that different signal transduction cascades involved in ERKI/II activation by different neurotransmitters suggest that fast (e.g., glutamergic) and modulatory (e.g., cholinergic) neurotransmission, both necessary for normal learning and memory, may converge on $\mathrm{ERKI} / \mathrm{II}$ in a given neuron. 


\section{MATERIALS AND METHODS}

Reagents. The pCD expression vectors containing the entire coding region of the rat M1 and the human M2, M3, and M4 mAChR were a gift from Dr. N. Buckley (University of Leeds). COS-7 cells were obtained from the European Collection of Cell Cultures. $\alpha$ MEM, HDMEME, EBSS, BME, HS, N2 supplement, and fibronectin were from Life Technologies (Gaithersburg, MD), and DMEM and DNase were from Sigma (St. Louis, MO). Hybond-ECL, nitrocellulose, ECL reagents, and film were from Amersham (Arlington Heights, IL). PP1, LY294002, PD98059, bisindolymaleimide-I HCl (BIM), and BAPTA-AM were from Calbiochem (La Jolla, CA). DNA plasmid maxipreparation kits were from Qiagen (Hilden, Germany). Precast tricine gels were from Novex. All other chemicals were of analytical grade or the highest grade available.

Electrophysiology and pharmacology. All procedures were performed in accordance with the United Kingdom Home Office Animals (Scientific Procedures) Act of 1986. Adult male Wistar rats (250-350 gm) were anesthetized with urethane $(1.8 \mathrm{mg} / \mathrm{kg}$, i.p.) and mounted in a stereotaxic frame. Four holes were drilled in the skull, and injection pipettes were lowered bilaterally to just above the dentate gyri $(4 \mathrm{~mm}$ caudal to bregma, $2.5 \mathrm{~mm}$ lateral, and $2.8 \mathrm{~mm}$ dorsal to pial surface). Concentric bipolar stimulating electrodes were placed bilaterally in the medial perforant paths $(4-4.2 \mathrm{~mm}$ lateral of lambda). Injections $(1 \mu \mathrm{l})$ of either $38 \mu \mathrm{M}$ PD098059 (test hemisphere) or $0.2 \%$ DMSO in saline (control hemisphere) were made over $10 \mathrm{~min}$, and the injection pipettes were then removed and replaced by recording micropipette (as for injections but 3.5 $\mathrm{mm}$ dorsal). Hilar field potentials evoked by perforant path stimulation were maximized, and then stimulation intensity was set to evoke a 1-3 $\mathrm{mV}$ population spike (60 $\mu$ sec pulses). Test responses were evoked at $0.033 \mathrm{~Hz}(1$ per $30 \mathrm{sec})$. Thirty minutes after drug or vehicle injection, tetanic stimulation was delivered to the perforant path (three trains of 50 pulses, $100 \mu \mathrm{sec}$ in duration, at $250 \mathrm{~Hz}, 30 \mathrm{sec}$ between trains). Test responses were sampled for an additional $20 \mathrm{~min}$, and then brains were removed and frozen on dry ice.

Pharmacology. Rats were injected intraperitoneally with atropine (50 $\mathrm{mg} / \mathrm{kg}$ ), physostigmine $(0.1 \mathrm{mg} / \mathrm{kg})$, or saline ( $2 \mathrm{ml}$ in total). Two hours after the injection, rats were decapitated, and the insular cortex (using the crossing of the rhinal fissure and the middle cerebral artery as a reference point) and hippocampus were excised on ice for immediate homogenization.

Hippocampal slice preparation. Sprague Dawley rats (200-250 gm) were stunned and decapitated, and the brain was removed and placed in cold $\left(4^{\circ} \mathrm{C}\right)$ oxygenated $\left(95 \% \mathrm{O}_{2}-5 \% \mathrm{CO}_{2}\right)$ artificial CSF. The hippocampus was removed bilaterally on ice. Slices $(400-\mu \mathrm{m}$-thick) were cut in a McIlwain tissue chopper and transferred to a holding chamber. The slices were allowed to recover for $3 \mathrm{hr}$ before being treated with the different drugs. After treatment, the slices $(n=3$ for each dose) were homogenized as described below. To check slice viability, in each experiment, one slice was transferred to a recording chamber and tested for the presence of evoked field potentials in CA1 area.

Primary cell cultures. Primary cultures were prepared according to Malgaroli and Tsien (1992), with minor modifications. Cells were plated to a density of 400,000 per well in a six-well plate.

Cell culture and transfection. These were performed as described previously (Jones et al., 1995). Briefly, mAChR subtypes M1-M4 were transiently expressed in COS-7 cells by electroporation using a Bio-Rad (Hercules, CA) Gene Pulser at $180 \mathrm{~V}$ and $960 \mathrm{mF}$ with $20 \mu \mathrm{g}$ of DNA/0.4 cm cuvette $\left(4 \times 10^{7}\right.$ cells, $\left.0.8 \mathrm{ml}\right)$.

Homogenization. Brain samples were homogenized in glass Teflon homogenizers in $300 \mathrm{ml}$ of SDS sample buffer (10\% glycerol, 5\% $\beta$-mercaptoethanol, and 2.3\% SDS, in $62.5 \mathrm{~mm}$ Tris HCl, pH 6.8). They were then boiled for $5 \mathrm{~min}$. Samples were immediately stored at $-20^{\circ} \mathrm{C}$ until further use. COS-7 cells or primary cortical neurons, which had been serum-starved overnight, were treated when specified with inhibitors and then stimulated with the mAChR agonist carbachol. After washing with PBSA, activation was halted by the addition of lysis buffer [1\% Triton X-100, $25 \mathrm{~mm}$ Tris, $\mathrm{pH} 7.5,150 \mathrm{~mm}$ sodium chloride, $1 \mathrm{~mm}$ EDTA, 1 mM EGTA, pH 8.0, 20 mm sodium fluoride, $1 \mathrm{~mm}$ sodium pyrophosphate, $1 \mathrm{~mm}$ DTT, $2 \mu \mathrm{M}$ protein kinase A inhibitor, $1 \mathrm{~mm}$ sodium vanadate, and $0.5 \%$ protease inhibitor cocktail (Sigma)]. Cells were removed from the wells using a rubber policeman and then spun at $4^{\circ} \mathrm{C}$ in a microfuge for 15 min to remove insoluble components. Supernatants were added to an equal amount of sample buffer ( $40 \%$ glycerol, $0.035 \%$ bromophenol blue, $15 \mathrm{~mm}$ DTT, and $2 \%$ SDS), snap frozen on dry ice, and stored at $-20^{\circ} \mathrm{C}$.
Western blot analysis. Aliquots in SDS-sample buffer were subjected to SDS-PAGE (Laemmli, 1970; Schagger and von Jagow, 1987) and Western blot analysis (Burnette, 1981). After the run, the blots were blocked with $1 \%$ BSA or $5 \%$ dried milk for $1 \mathrm{hr}$ at room temperature. The blots were reacted either overnight in a cold room or $1 \mathrm{hr}$ at room temperature with primary antibody. After three short washes, the blots were subsequently incubated for $1 \mathrm{hr}$ at room temperature with HRP-linked protein A, Protein G-HRP (Zymed, San Francisco, CA), or HRP-conjugated anti-rabbit $\operatorname{IgG}$ or anti-mouse $\operatorname{IgG}$ (Amersham). The blots were then exposed to ECL substrate and film (Amersham). The primary antibodies used were dually phosphorylated (dp) ERKI/II [1:30000 (Promega, Madison, WI; 1:5000 (New England Biolabs, Beverly, MA)], dpSAPK/ JNK (1:1000; New England Biolabs), and ERKI/II (1:2000; New England Biolabs). Usually the blots were first treated with anti-dpERKI/II antibody, stripped with stripping buffer (100 mM $\beta$-mercaptoethanol, $2 \%$ SDS, and $62.5 \mathrm{~mm}$ Tris-HCl, pH6.7), and reprobed with anti-ERKI/II antibody.

Quantification was performed using computerized densitometry and an image analyzer (Molecular Dynamics, Sunnyvale, CA). Differences between two groups were determined using two-way Student's $t$ test ( $\alpha$ level of 0.05).

\section{RESULTS}

\section{ERKI/II activation is necessary for in vivo LTP and is modulated by intrinsic muscarinic acetylcholine receptors in the cortex and the hippocampus}

ERKI/II activity has been found to be both necessary for and correlated with several forms of synaptic plasticity and learning (Orban, 1999). These include the most intensively studied cellular model of learning and memory, LTP, in a brain slice preparation (English and Sweatt, 1997). The slice preparation is different from the intact brain in two major ways: first, it does not include an intact modulatory input from distal brain areas, and second, there is mechanical damage to the cut tissue. For these reasons, we examined the role of ERKI/II in LTP in the DG of intact, anesthetized animals. Because no specific ERKI/II inhibitors are available, we examined the effect of PD98059, an inhibitor of ERKI/II kinase [MAP kinase/ERK kinase (MEK)], on the magnitude and duration of LTP in the DG. MEK is the kinase directly upstream of ERKI/II responsible for the dual phosphorylation of ERKI/II on tyrosine and threonine residues and hence its activation. PD98059 was microinjected into the DG of one hemisphere $30 \mathrm{~min}$ before the induction of LTP (Fig. 1A, arrowhead), and vehicle alone was injected into the contralateral hemisphere. Tetanic stimulation was then delivered 30 min later to the perforant path in both hemispheres (small arrowheads). Normalized data from four animals shows that the percentage change in the slope of field EPSP after tetanic stimulation was significantly $(p<0.04$; paired $t$ test) larger in the hemisphere injected with vehicle compared with the hemisphere injected with the MEK inhibitor PD98059 (Fig. 1A). This result suggests that ERKI/II plays a necessary role in the induction of LTP in the DG in vivo.

What might modulate the degree of ERKI/II activity in the intact brain? In neurons, ERKI/II can be activated by glutamate via $\mathrm{Ca}^{2+}$-dependent mechanisms (Xia et al., 1996). To assess the contribution of mAChRs to ERKI/II activation in the brain, we quantified the amount of ERKI/II phosphorylation in cortical and hippocampal tissue following procedures that either increased levels of acetylcholine (after intraperitoneal administration of physostigmine, an acetylcholinesterase inhibitor) or decreased activity of mAChRs by intrinsic acetylcholine (after intraperitoneal administration of atropine, an $\mathrm{mAChR}$ antagonist). The doses of physostigmine and atropine used were in the range reported to have effects on behavior (Beninger et al., 1989). ERKI/II activation is increased after injection of physostigmine and reduced after injection of atropine (Fig. 1B). Together, these 
A

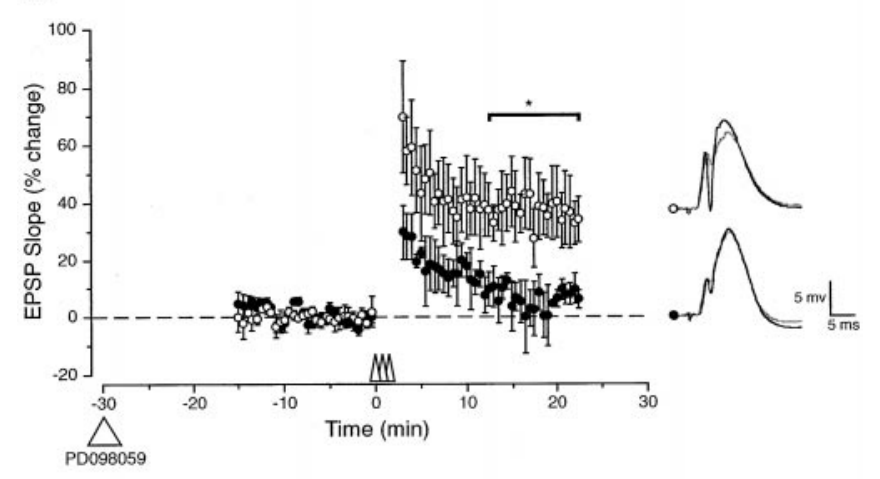

B
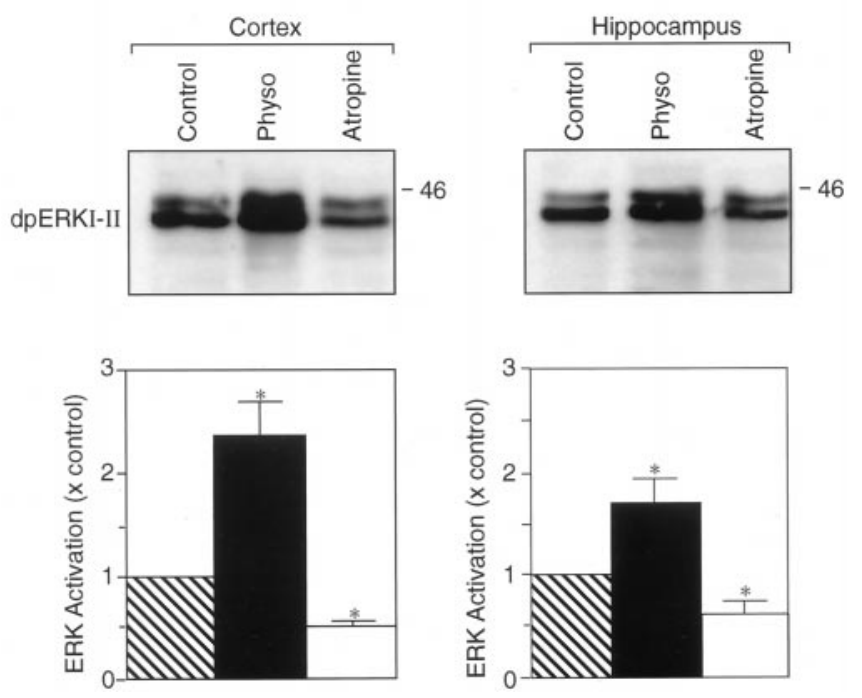

Figure 1. A, LTP in the dentate gyrus in vivo is ERKI/II-dependent. Rats were anesthetized and prepared for bilateral recording from the DG and for bilateral stimulation of the medial perforant path. Injections $(1 \mu \mathrm{l})$ of the MEK inhibitor PD98059 (38 $\mu \mathrm{M}$, test hemisphere; filled circles) or vehicle only ( $0.2 \%$ DMSO, control hemisphere; open circles) were made over $10 \mathrm{~min}$ (large arrowhead indicates the end of the $10 \mathrm{~min}$ injection period). The injection pipettes were then removed and replaced by micropipette recording electrodes. Test responses were evoked at intervals of $30 \mathrm{sec}$, beginning $15 \mathrm{~min}$ after drug or vehicle injection. Small arrowheads indicate bilateral delivery of tetanic stimulation. There was a significant difference in the slope of the field EPSP in the two sides measured 20-30 min after the tetanus; LTP was induced in the control side but was minimal in the MEK-inhibited side after the decay of short-term potentiation was observed. ${ }^{*} p=0.4$; paired $t$ test. The traces on the right show superimposed pairs of test responses before (light traces) and 15 min after (darker traces) the induction of LTP in the control and drug-injected sides (top and bottom pairs, respectively). $B$, ERKI/II activation is modulated by intrinsic acetylcholine activity in the cortex and hippocampus in vivo. Rats were injected intraperitoneally with saline (striped bars), the acetylcholinesterase inhibitor physostigmine $(0.1 \mathrm{mg} /$ $\mathrm{kg}$; physo, black bars), or the mAChR antagonist atropine $(50 \mathrm{mg} / \mathrm{kg}$; white bars). Activated ERKI/II (dpERKI/II) was assayed in the hippocampus and the insular cortex $(n=4$ brains) by Western blots (top). The mean \pm SEM ratio between ERKI/II intensity in the control and the experimental groups is plotted in the histograms. Representative immunoblots for the different treatments in the hippocampus and cortex are displayed above. In both regions, a significant increase in ERKI/II activity was seen after treatment with physostigmine, whereas atropine caused a decrease in ERKI/II activity. ${ }^{*} p<0.05$; Student's $t$ test. In this and all subsequent figures, the amount of the ERKI/II protein was determined using anti-ERKI/II protein. No differences in the amount of ERKI/II protein were detected. results show that $\mathrm{mAChRs}$ are linked to ERKI/II activation in the hippocampus and cortex and that ERKI/II activation is necessary for LTP in vivo. We next sought to analyze the conditions and signal transduction pathways involved in ERKI/II activation by mAChRs in neurons.

\section{Carbachol induces a dose-dependent activation of ERKI/II in brain slices, primary cortical neurons, and COS-7 cells expressing the different mAChR subtypes (M1-M4)}

In our experiments on brain slices, we found that the basal level of ERKI/II activation varied between slices. This variation in basal expression may reflect a variety of causes, such as different amounts of damage to the tissue during slice preparation or maintenance. Irrespective of this variation, application of increasing doses of carbachol induced a dose-dependent activation of ERKI/II (Fig. 2A, top panel). A submicromolar dose of carbachol was enough to induce ERKI/II activation. A similar dosedependent pattern of ERKI/II activation was seen using increasing doses of insulin, which acts on a receptor tyrosine kinase (RTK) (Fig. 2A, bottom panel). To analyze the molecular pathway involved in ERKI/II activation by mAChRs in a more stable system, we examined ERKI/II activation in primary cortical neurons (12-14 d in culture) and, in parallel, used a COS-7 cell line as a model system for the individual expression of each mAChR subtype. A similar pattern of expression of mAChRs is seen in cortical neurons in primary culture as in vivo (Eva et al., 1990; Andre et al., 1994). The COS-7 cell line does not endogenously express mAChRs but can be transiently transfected with each mAChR subtype to ascertain muscarinic subtype-specific effects on ERKI/II activation. Increasing doses of carbachol resulted in increasing activation of ERKI/II in primary cortical neurons (Fig. $2 B$ ). In the presence of $1 \mu \mathrm{M}$ TTX, a similar amount of ERKI/II activation (ratio of $3.73 \pm 0.16$ over basal; $n=4$ ) was detected after $1 \mathrm{hr}$ incubation with $100 \mu \mathrm{M}$ carbachol as was seen in the absence of TTX, suggesting that in primary cortical neurons ERKI/II activation is activity-independent. In COS-7 cells transiently expressing one or another of the M1-M4 subtypes, increasing doses of carbachol induced an increasing ERKI/II activation (Fig. 2C). ERKI/II activation was atropine-dependent in both preparations (see Fig. 5), and thus mAChR-dependent. The differences in the sensitivity of ERKI/II activation may reflect differences in receptor expression levels and thus is not necessarily an indication of differences in the ability to activate the MAPK cascade. However, because M1, M2, and M4 are expressed at similar levels (data not shown), it is possible that M1 activates ERKI/II more efficiently than M2 and M4.

\section{Carbachol induces prolonged activation of ERKI/II but not SAPK/JNK in primary cortical neurons and cOS-7 cells}

The time course of ERKI/II activation was found to be crucial for determining its effect on the differentiation of PC12 cells (Marshall, 1995). In novel taste learning for which functional mAChRs in the taste cortex are necessary, different time scales of activation were detected for ERKI/II and SAPK/JNK (Berman et al., 1998). We therefore analyzed the time course of ERKI/II activation by carbachol in primary cortical neurons. Carbachol induces prolonged ERKI/II activation (over $4 \mathrm{hr}$ ), peaking 30-60 min after carbachol administration, but does not activate SAPK/ JNK (Fig. 3A).

In COS-7 cells expressing the different mAChR subtypes, ERKI/II was activated with a more rapid time course than in 


\section{A}
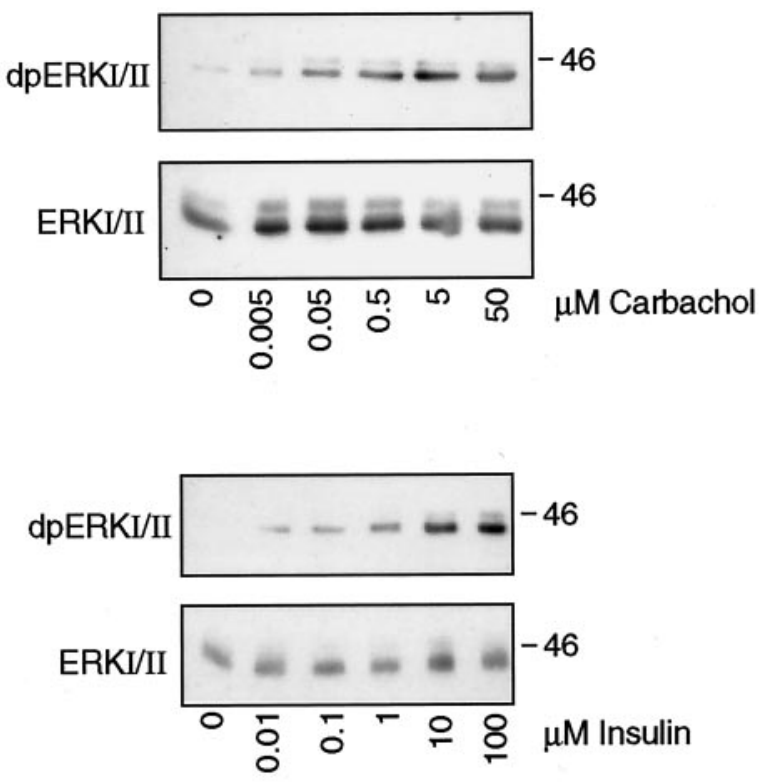

B

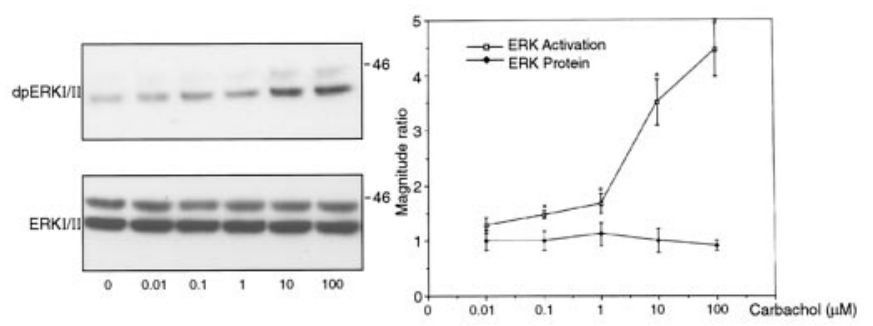

C

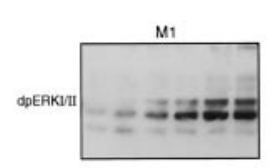

M2
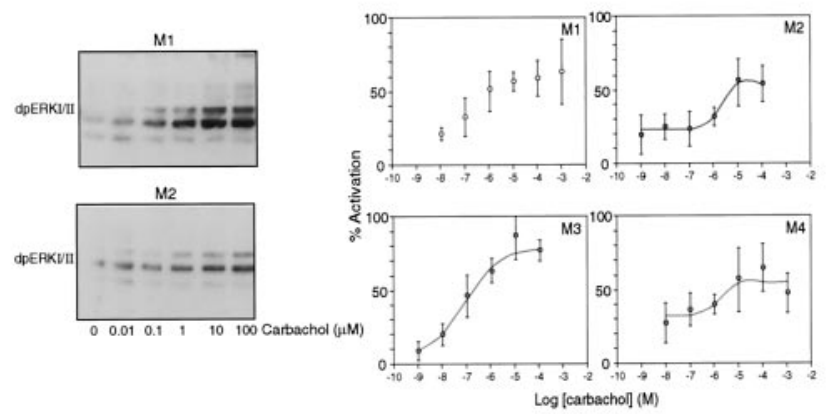

Figure 2. Dose-dependent activation of ERKI/II by carbachol in hippocampal slices $(A)$, primary cortical neurons $(B)$, and COS-7 cells expressing the different mAChRs $(C) . A$, Carbachol and insulin induce ERKI/II activation in hippocampal slices in a dose-dependent manner. Slices were incubated with increasing doses of carbachol (top panels) or insulin (bottom panels) as indicated and were processed for immunoblotting with anti-dpERKI/II primary antibody $30 \mathrm{~min}$ after addition of the drugs (the time at which activation was maximal; see Fig. 3). B, Carbachol induces ERKI/II activation in primary cortical neurons in a dosedependent manner. Cell extracts were processed for immunoblots $30 \mathrm{~min}$ after administration of different doses of carbachol as indicated in the graph (right). The graph indicates the ratio of the magnitude of ERKI/II activation in the presence and absence of carbachol at each concentration primary neurons, peaking $10 \mathrm{~min}$ after carbachol administration (Fig. 3B). The difference in time course of ERKI/II activation between transfected COS-7 and neurons might be attributable to higher levels of expression in the COS-7 cells or to different signal transduction mechanisms involved in the activation and deactivation of ERKI/II in these two cell types. We favor the second explanation because, in HEK-293 cells, which express low levels of M3 mAChRs endogenously, the peak timing of ERKI/II activation is similar to that seen in COS-7 cells when expressing the different mAChR subtypes (M1-M4) (M. Futter, unpublished results).

\section{ERKI/II activation by carbachol is Src-dependent and PKC-independent}

The signal transduction pathway involved in ERKI/II activation by receptor tyrosine kinases and by G-protein-coupled receptors has been extensively investigated in cell lines (Sugden and Clerk, 1997). However, limited results are available for neuronal systems (Fukunaga and Miyamoto, 1998). We have used pharmacological inhibitors to assess the signal transduction pathways involved in the $\mathrm{mAChR}$ activation of ERKI/II in primary cortical neurons and in the COS-7 model system expressing different mAChR subtypes. In all of these experiments, inhibition was expressed as percentage with respect to the level of ERKI/II activation by 100 $\mu \mathrm{M}$ carbachol. BAPTA-AM and EGTA were applied for $1 \mathrm{hr}$ and $10 \mathrm{~min}$, respectively, before carbachol administration. The combined application of chelators of both intracellular and extracellular $\mathrm{Ca}^{2+}$ (BAPTA-AM and EGTA, respectively) only weakly attenuated ERKI/II activation by carbachol in both primary cultures and COS-7 cells expressing the different muscarinic receptors (Fig. 4A,B). The minimal dependency on $\mathrm{Ca}^{2+}$ is interesting given the ability of $\mathrm{mAChRs}$ to release $\mathrm{Ca}^{2+}$ from intracellular stores in variety of cell types (Felder, 1995). Moreover, the fact that stimulated NMDA receptors affect ERKI/II activation in a $\mathrm{Ca}^{2+}$-dependent manner (Fig. 4C) suggests that NMDA- and mAChR-mediated signaling within a neuron can converge on the ERKI/II protein via different molecular pathways.

We further analyzed the involvement of postulated kinases known to mediate effects downstream of G-protein activation. At least three kinases have been implicated in ERK activation in different cell lines: (1) PKC, converging at the level of Raf, (2) $\mathrm{PI}_{3} \mathrm{~K}$, and (3) Src, which both converge at the level of the ternary complex Shc-Grb2-Sos1 (Lopez-Ilasaca et al., 1998). Addition of the PKC inhibitor BIM (1 $\mu \mathrm{M}) 15$ min before carbachol administration did not affect ERK activation by carbachol in primary cortical neurons or COS-7 cells expressing the M1 mAChR ( $8 \pm 8 \%$ in primary neurons; $n=9$; and $20 \pm 5 \%$ in COS-7 cells; $n=6$ ) (Fig. $5 B$ ). Administration of $20 \mu \mathrm{M}$ LY294002, an inhibitor of $\mathrm{PI}_{3} \mathrm{~K}, 15$ min before agonist activation, attenuated carbachol-mediated ERK activation by $68 \pm 7 \%$ in primary cortical neurons $(n=8)$ and by $56 \pm 7 \%$ in COS-7 cells expressing the M1 mAChR subtypes $(n=8)$ (Fig. $5 B)$. Last,

$\leftarrow$

examined $(n=4)$. ${ }^{*} p<0.5$; Student's $t$ test. $C$, Carbachol induces a dose-dependent activation of ERKI/II in COS-7 cells expressing the different mAChRs (M1-M4). Cells were incubated for $10 \mathrm{~min}$ with a given concentration of carbachol, and the degree of ERKI/II activation produced by that dose was expressed as a percentage of the maximal activation produced by $1 \mathrm{ng} / \mathrm{ml}$ epidermal growth factor (defined as $100 \%)(n=4)$. Representative blots from cells expressing the M1 and M2 receptors are shown at the left. ${ }^{*} p<0.5$; Student's $t$ test. 


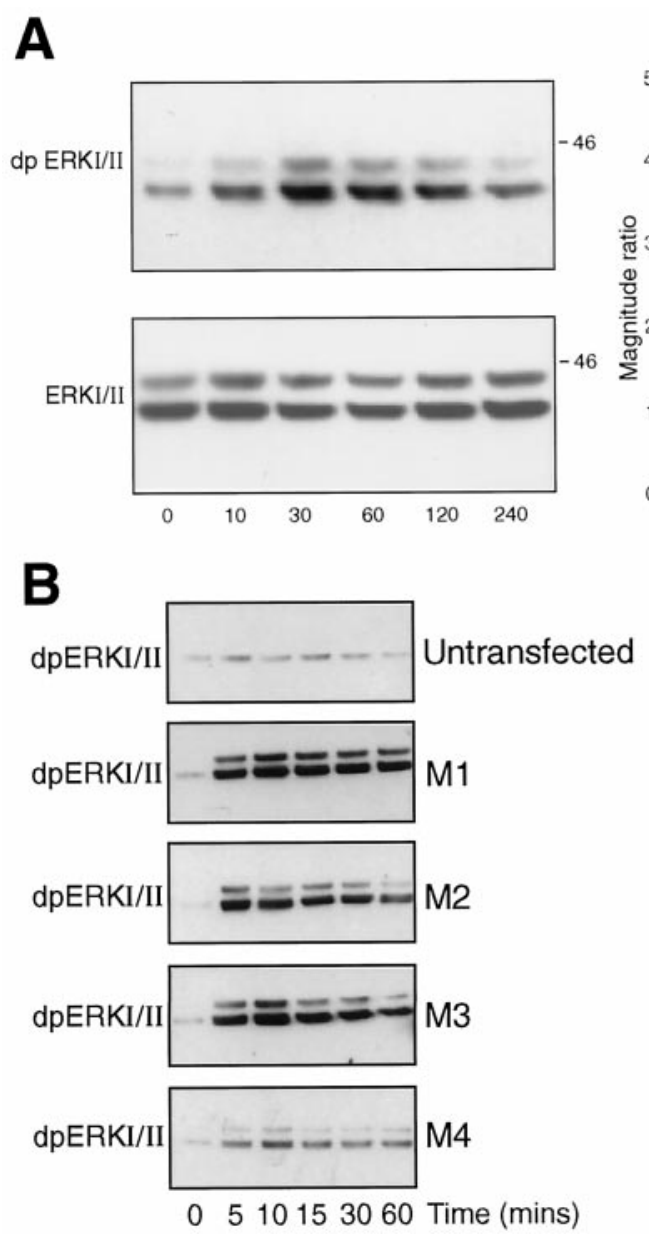

Figure 3. Time course of activation of two members of the MAPK family (ERKI/II and SAPK/JNK) by carbachol in primary cortical cultures $(A)$ and COS-7 cells expressing the muscarinic receptors M1-M4 $(B)$. $A$, Carbachol induces prolonged activation of ERKI/II but not SAPK/JNK in primary cortical neurons. Primary cortical neurons were incubated for different times in carbachol $(100 \mu \mathrm{M})$. Carbachol induced a prolonged activation of ERKI/II (over $4 \mathrm{hr}$ ) that peaked between 30 and $60 \mathrm{~min}$ after addition of the drug. No changes were observed in the amount of the ERKI/II protein or in the activation of SAPK/JNK. ${ }^{*} p<0.5$; Student's $t$ test $(n=4)$. Representative immunoblots for dpERKI/II and ERKI/II are shown at the left. $B$, Carbachol induces prolonged activation of ERKI/II in COS-7 cells expressing the different mAChRs M1-M4. COS-7 cells expressing one of the four mAChRs were incubated in $100 \mu \mathrm{M}$ carbachol and followed for different time intervals. Carbachol induced a prolonged activation of ERKI/II, which peaked $\sim 10$ min after carbachol administration. No change was observed in the amount of ERKI/II protein after treatment with carbachol, and no ERKI/II activation was observed in nontransfected COS-7 cells. ${ }^{*} p<0.5$; Student's $t$ test $(n=4)$. addition of $10 \mu \mathrm{M}$ PP1, an inhibitor of the Src family of tyrosine kinases, 15 min before carbachol administration, attenuated ERK activation by carbachol by $91 \pm 7 \%$ in primary cortical neurons $(n=8)$ and by $103 \pm 2 \%$ in COS- 7 cells expressing the M1 mAChR subtypes $(n=8)$ (Fig. $5 A)$. The values of inhibition for COS-7 cells expressing the M1 mAChR described above were similar to values of inhibition for COS-7 cells expressing the M2 mAChR (data not shown).

The above results demonstrate the likely involvement of $\mathrm{PI}_{3} \mathrm{~K}$ and the Src family of tyrosine kinases in regulating activation of the ERK pathway by mAChRs. Several Src families are highly expressed in the brain and have been found to be obligatory for LTP in the hippocampus (Salter, 1998). In particular, Fyn, a member of the Src family, has been implicated in LTP (Grant et al., 1992). We thus analyzed ERK activation by carbachol in primary cortical cultures from Fyn knock-out mice. However, carbachol retained its ability to induce a dose-dependent ERK activation in these cultures (Fig. 5C).

\section{DISCUSSION}

The results presented here reveal strong biochemical connections in neurons between two classes of molecules involved in learning and memory, mAChRs and the MAPKs. There is a good deal of evidence linking $\mathrm{mAChRs}$ to cognitive processes, such as learning and memory (Blokland, 1995), but their role at the cellular and molecular levels in these processes is less clear. The development of new reagents for studying the MAPK signal transduction pathway (e.g., phospho-specific antibodies and selective
MEK inhibitors) has led to studies suggesting specific roles for ERKI/II in learning and memory (Berman et al., 1998; Blum et al., 1999) and synaptic plasticity (English and Sweatt, 1997; Martin et al., 1997; Coogan et al., 1999). Here, we demonstrate that the MEK inhibitor PD98059 blocks LTP, indicating that activation of ERKI/II plays an obligatory role in the induction of LTP in the dentate gyrus in vivo. We also show that physostigmine increased, and atropine decreased, endogenous ERKI/II activity, thus establishing a physiological connection between mAChR occupancy and ERKI/II activity in the cortex and hippocampus. We characterize the dose-response relationship and time course of the mAChR-mediated activation of ERKI/II and SAPK/JNK. Finally, we characterize the signal transduction pathway involved in $\mathrm{mAChR}$-mediated activation of ERKI/II in neurons and in COS-7 cells expressing one or another of the different $\mathrm{mAChR}$ subtypes. In both neurons and fibroblasts, this activation is Srcdependent but only partially dependent on $\mathrm{PI}_{3} \mathrm{~K}$ and $\mathrm{Ca}^{2+}$. ERKI/II activation by carbachol is not, however, PKCdependent. These findings demonstrate a crucial role for ERKI/II activation in synaptic plasticity in the intact animal and identify ERKI/II as a target for mAChR-mediated action in neurons. The available data suggests that, in neurons, stimuli from different receptors can converge on ERKI/II (Fig. 6).

We have shown that PD98059 prevents the development of LTP in the dentate gyrus of the anesthetized rat, extending to the intact preparation the observation by English and Sweatt (1997) and Coogan et al. (1999) that the drug severely attenuates LTP in 


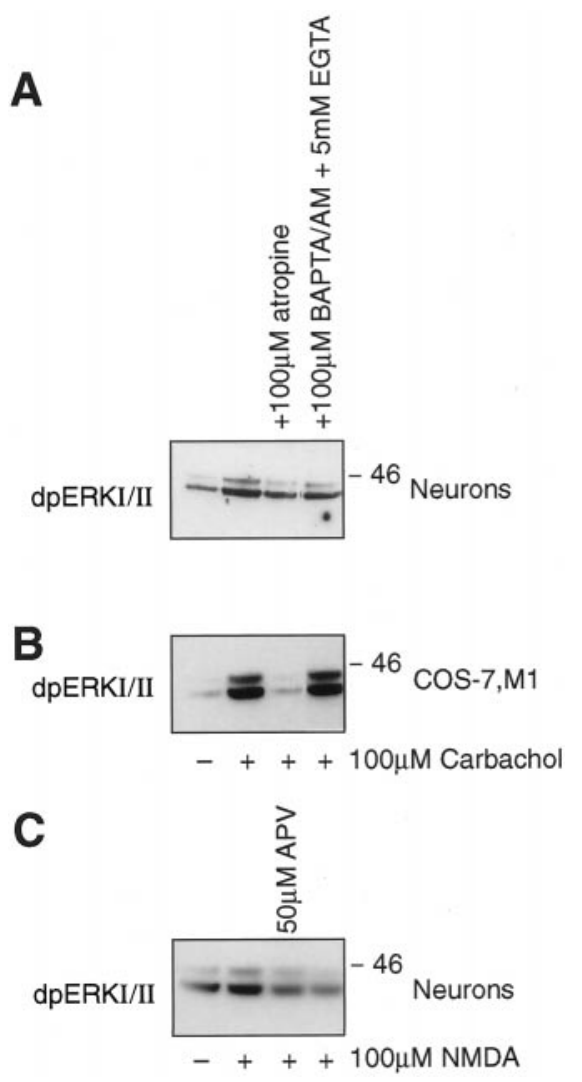

Figure 4. $\mathrm{Ca}^{2+}$ chelators block ERKI/II activation by NMDA but not by carbachol in primary cortical neurons. $A$, ERKI/II activation by mAChRs is attenuated but not blocked by $\mathrm{Ca}^{2+}$ chelators in primary cortical cultures. Primary cortical cultures were treated with carbachol, or with carbachol plus $100 \mu \mathrm{M}$ BAPTA-AM and 5 mM EGTA. The $\mathrm{Ca}^{+2}$ chelators attenuated ERKI/II activation but did not block it. The immunoblot is representative of four different experiments. $B$, ERKI/II activation by mAChRs is not blocked by $\mathrm{Ca}^{2+}$ chelators in COS-7 cells expressing the M1 receptor. COS-7 cells expressing the M1 mAChR were treated with carbachol or carbachol plus $100 \mu \mathrm{M}$ BAPTA-AM and 5 mM EGTA. $\mathrm{Ca}^{2+}$ chelators do not block ERKI/II activation. The immunoblot is representative of four different experiments. $C$, NMDA induces ERKI/II activation in a $\mathrm{Ca}^{2+}$-dependent manner. Primary cortical cultures were treated for 10 min with $100 \mu \mathrm{M}$ NMDA, with NMDA and $50 \mu \mathrm{M}$ APV, or with NMDA plus $100 \mu \mathrm{M}$ BAPTA-AM and 5 mM EGTA. Both the NMDA channel antagonist and the $\mathrm{Ca}^{2+}$ chelators blocked the effect of NMDA on ERKI/II activation; the blot is representative of three different experiments.

area CA1 or DG of the hippocampal slice. Our experimental design, with vehicle injected into one hemisphere and PD98059 into the other, ensures that any difference in LTP is attributable to the drug. The drug at the concentration used here has been found to be highly selective (Alessi et al., 1995). This, together with the fact that ERKI/II is the only known substrate of MEK, allows us to conclude that activation of ERKI/II is necessary for the successful induction of LTP in the dentate gyrus of the intact animal (Fig. 1A). Potentiation in the hemisphere treated with the MEK inhibitor PD98059 was reduced in the initial magnitude relative to the control hemisphere and decayed to baseline over a period of $\sim 20 \mathrm{~min}$. Thus, in the hippocampus, as in the insular cortex (Jones et al., 1999), block of ERKI/II activation prevents both early and late phases of LTP, leaving only a residual period of short-term potentiation.

Pharmacological measurements in the behaving animal have established that novel stimuli can cause a release of acetylcholine
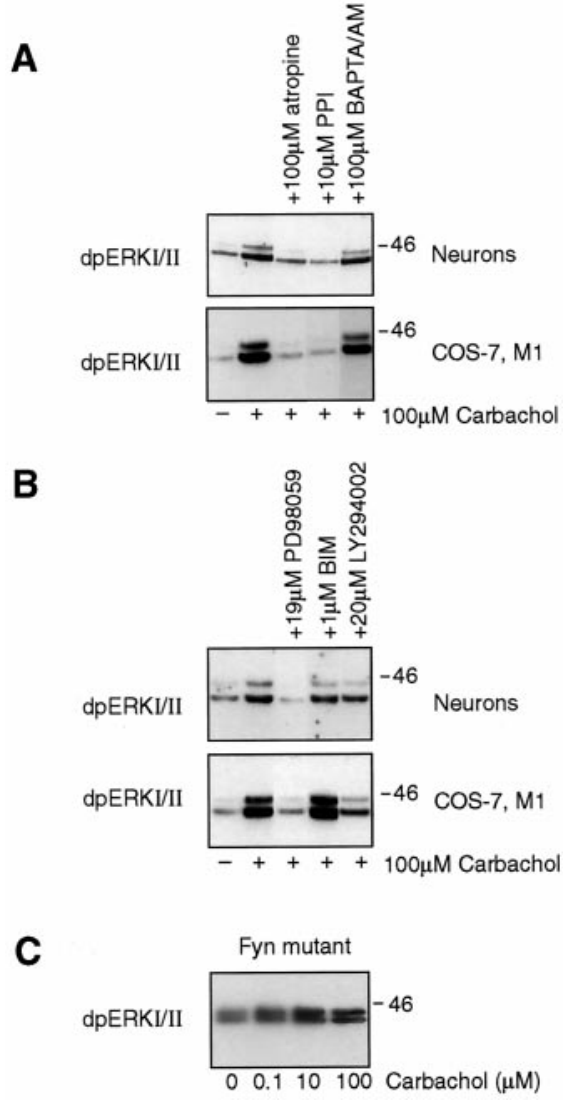

Figure 5. ERKI/II activation by $\mathrm{mAChR}$ is Src-dependent and partially $\mathrm{PI}_{3} \mathrm{~K}$ - and $\mathrm{Ca}^{2+}$-dependent but is $\mathrm{PKC}$-independent. $A$, The Src inhibitor PP1 inhibits ERKI/II activation by carbachol. Carbachol $(100 \mu \mathrm{M})$ induces ERKI/II activation in primary cortical cultures and in COS-7 cells expressing the M1 receptor. Activation was blocked by $100 \mu \mathrm{M}$ atropine or $10 \mu \mathrm{M}$ PP1 and attenuated by $100 \mu \mathrm{M}$ BAPTA-AM. The blot is representative of triplicates from three different experiments. $B$, The $\mathrm{PI}_{3} \mathrm{~K}$ inhibitor LY294002 attenuates ERKI/II activation by carbachol, but the PKC inhibitor BIM is ineffective. Carbachol $(100 \mu \mathrm{M})$ induces ERKI/II activation in primary cortical cultures and COS-7 cells expressing the M1 receptor. The activation was blocked by the MEK inhibitor PD98059 (19 $\mu \mathrm{M})$, attenuated by the PI3K inhibitor LY294002 (10 $\mu \mathrm{M})$, and unaffected by the PKC inhibitor BIM $(1 \mu \mathrm{M})$. The blot is representative of triplicates from three different experiments. $C$, Fyn is not necessary for ERKI/II activation by carbachol. Primary cortical cultures were prepared from Fyn knock-out mice. The cultures show dose-dependent activation of ERKI/II by carbachol.

in the cortical area (Acquas et al., 1996). We imitated this increase in release of acetylcholine by bath application of the mAChR agonist carbachol to hippocampal slices and to primary cortical cells in culture. Carbachol induces a prolonged dosedependent activation of ERKI/II in the slice preparation and in primary cortical cells (Fig. $2 A, B$ ). The pattern of expression of the mAChRs in the brain is different for each subtype, and the coupling to different G-proteins can induce different signal transduction pathways (Wess, 1996). However, using the COS-7 model system, we have found that all four of the mAChR subtypes (M1-M4) can induce ERKI/II activation in a dose-dependent manner (Fig. 2C).

The duration of ERKI/II activation can be crucial in the determination of differentiation versus division in PC12 cells. Prolonged activation, which leads to differentiation, is associated with ERKI/II-dependent modulation of gene induction (Mar- 


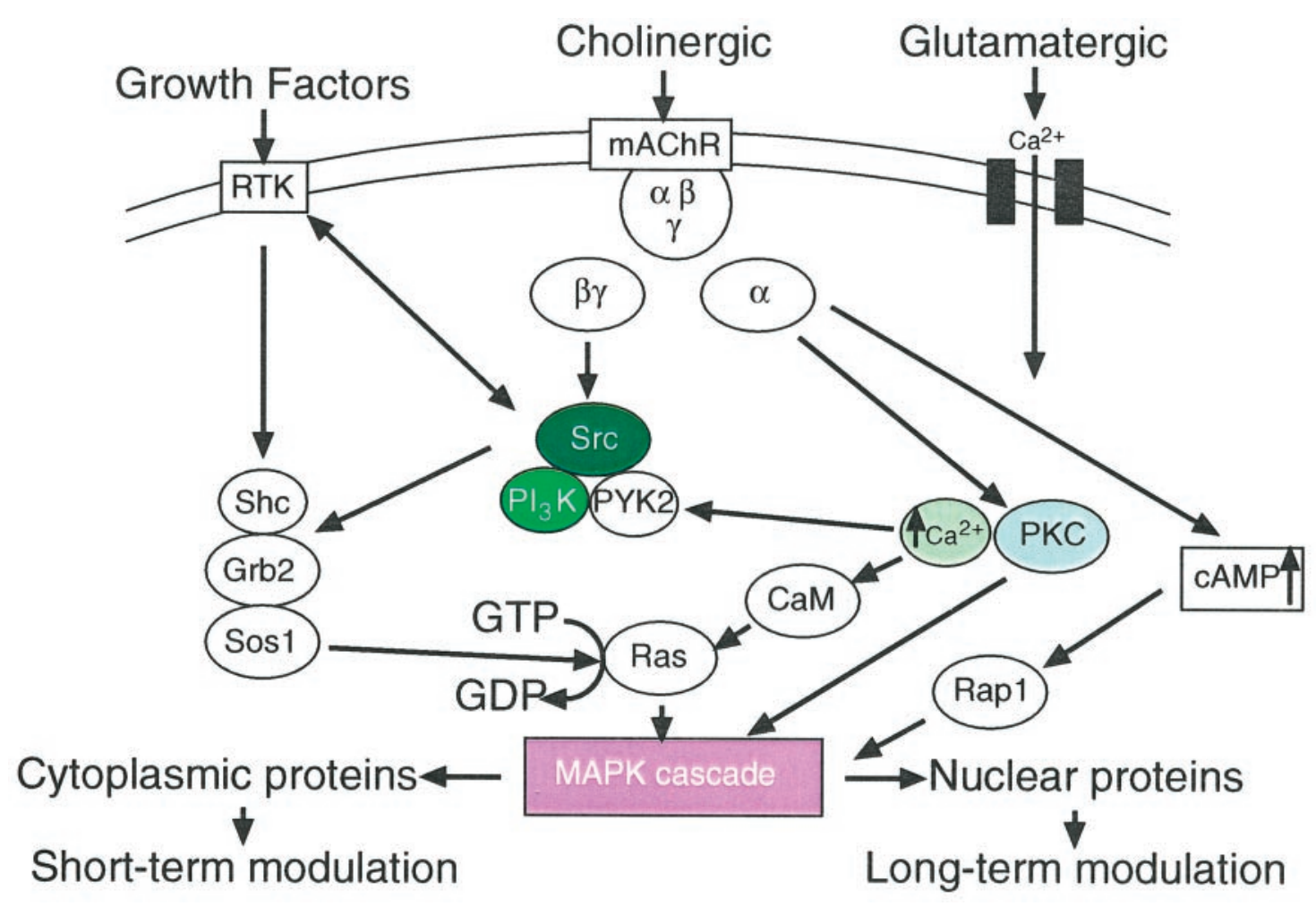

Figure 6. ERKI/II (MAPK) can serve as a convergence site for multiple extracellular signals known to induce plasticity in mature neurons. The best documented activation of the MAPK cascade occurs via ligand binding to RTK. Mature neurons express high levels of different RTKs, demonstrated in this work by the insulin receptor (Fig. 2A). Activation of RTK recruits the Shc-Grb2-SOS1 complex, which in turn activates Ras. Ras induces MAPK activation via an evolutionarily conserved pathway, which includes Raf, MEK (MAPKK), and ERKI/II (MAPK) (all included here within $M A P K$ cascade). ERKI/II is known to have both cytoplasmic (e.g., glycogene synthase kinase) and nuclear (e.g., Elk-1) targets and can translocate to the nucleus to modulate transcription in neurons. The block of LTP induction by the MEK inhibitor PD98059 (Fig. 1A) suggests that MAPK plays a role in the early phase of LTP, which is dependent on modulation of membranal or cytosolic proteins. Another documented pathway by which MAPK is activated in neurons is via glutamate receptors, represented here by the NMDA receptor, activation of which lead to increased levels of intracellular $\mathrm{Ca}^{2+}\left(\mathrm{Fig}^{2}\right.$. 4). Increased intracellular $\mathrm{Ca}^{2+}$ may modulate the MAPK cascade via activation of a $\mathrm{Ca}^{2+}$-dependent tyrosine kinase $(P Y K 2)$ or calmodulin $(C a M)$. The main pathway studied here is one mediated by mAChRs. Different mAChR subtypes can activate different signaling cascades, which depends on the dissociated $\alpha$ and $\beta \gamma$ subunits. All four (M1-M4) mAChRs can induce MAPK activation when expressed in the COS-7 cell line (Fig. 2). The signal transduction in neurons shows Src-dependence and $\mathrm{PKC}$-independence, whereas both $\mathrm{PI}_{3} \mathrm{~K}$ and $\mathrm{Ca}^{2+}$ can modulate mAChR-mediated MAPK activation (Fig. 5). In neurons, the major pathway by which mAChRs induce MAPK activation is via $\beta \gamma$, using a Src- and PI ${ }_{3} \mathrm{~K}-d e p e n d e n t ~ m e c h a n i s m$. Cross-talk between the different signal transduction cascades may occur at multiple levels. The prolonged duration of MAPK activation suggests that convergence from different extracellular stimulus may take place in a time domain of minutes to hours.

shall, 1995). Impey et al. (1998) reported that ERKI/II signaling is necessary for $\mathrm{Ca}^{2+}$-stimulated transcription in hippocampal neurons and PC12 cells. In neurons, as well as in COS-7 cells, carbachol induces prolonged activation of ERKI/II (Fig. $3 A, B$ ). It has been reported recently that two members of the MAPK family, ERKI/II and SAPK/JNK, are activated at different time scales after learning (Berman et al., 1998). We thus analyzed the activation of the SAPK/JNK in both neurons and COS-7 cells expressing the different $\mathrm{mAChR}$ subtypes after carbachol stimulation. We found no indication that SAPK/JNK was activated in either system up to $4 \mathrm{hr}$ after stimulation (Fig. 3).

In neurons and PC12 cells, ERKI/II can be activated via increased cytosolic $\mathrm{Ca}^{2+}$ (Xia et al., 1996). mAChRs can increase intracellular $\mathrm{Ca}^{2+}$ by either membrane depolarization with consequent activation of voltage-gated $\mathrm{Ca}^{2+}$ channels or release from intracellular stores (Felder, 1995). We tested the ability of both the intracellular $\mathrm{Ca}^{2+}$ chelator BAPTA-AM and the extracellular $\mathrm{Ca}^{2+}$ chelator EGTA to inhibit ERKI/II activation by $\mathrm{mAChR}$. Significantly, the $\mathrm{Ca}^{2+}$ chelators abolished the NMDA-dependent, but not the mAChR-dependent, ERKI/II activation (Fig. 4), indicating that an alternative signal transduction pathway is involved in ERKI/II activation by $\mathrm{mAChR}$.
We were interested in the role of three kinases known to be downstream of G-proteins and upstream of ERKI/II: PKC, $\mathrm{PI}_{3} \mathrm{~K}$, and the Src family of tyrosine kinases. Using kinase-specific inhibitors, we found that, in both cortical neurons and COS-7 cells expressing the different mAChR subtypes, ERKI/II activation is Src-dependent and partially $\mathrm{PI}_{3} \mathrm{~K}$ - and $\mathrm{Ca}^{2+}$-dependent but PKC-independent (Fig. 5).

What might be the signal transduction pathway involved in $\mathrm{Ca}^{2+}$ - and PKC- independent ERKI/II activation? In cell lines, different G-protein-coupled receptors can activate ERKI/II via $\mathrm{G}_{\mathrm{i} / \mathrm{o}^{-}}$or $\mathrm{G}_{\mathrm{q}}$-proteins through the $\alpha$ and $\beta \gamma$ subunits (Crespo et al., 1994; Koch et al., 1994). Activation by $\mathrm{G}_{\alpha}$ in different cell lines has been found to be PKC- and/or $\mathrm{Ca}^{2+}$-dependent (Hawes et al., 1995; Della Rocca et al., 1999). The control of ERKI/II activation by mAChRs seems similar in neurons and COS-7 cells. In both, there is a central role for Src kinase and an involvement of $\mathrm{PI}_{3} \mathrm{~K}$ (Figs. 4, 5). We propose that, in both neurons and the COS-7 model system, ERKI/II activation by mAChRs is primarily induced by the $\mathrm{G}_{\beta \gamma}$ (Fig. 6). It has been suggested that G-protein-coupled receptors and RTKs can induce p21ras activation via assembly of a p21ras activation complex at the plasma membrane (Koch et al., 1994). This assembly, which contains 
proteins similar to those used by RTKs, is dependent on $G_{\beta \gamma^{-}}$ mediated tyrosine kinase activation (Fig. 6). Indeed, we have observed a general increase in tyrosine phosphorylation in brain (Rosenblum et al., 1996) hippocampal slices and in primary neurons after activation of the mAChR (K. Rosenblum and M. Futter, unpublished data).

What might be the crucial role played by ERKI/II in synaptic plasticity? We suggest that the ERKI/II can serve as a point of convergence between different signal transduction cascades in fully differentiated neurons to produce plasticity. BDNF acting on the TrkB receptor (Lu and Figurov, 1997), carbachol acting on the mAChRs (Auerbach and Segal, 1996), and glutamate acting on the NMDA receptor (Collingridge et al., 1983) can all induce LTP and strong ERKI/II activation. It would be interesting to explore the ERKI/II dependency of other two forms of LTP, i.e., those mediated by carbachol and BDNF. ERKI/II can thus serve as the biochemical integration point for the ionotropic neurotransmission represented in our model by the NMDA receptor and the modulatory transmission represented by the mAChR (Fig. 6). From the intracellular perspective, ERKI/II serves as a detector of several signal transduction pathways, including, $\mathrm{Ca}^{2+}$ dependent cAMP-dependent events (Impey et al., 1998) (Fig. 6). The prolonged activation of ERKI/II detected in neurons suggests that the temporal domain in which such integrative processes can take place is much longer than the one used by fast neurotransmission alone (minutes to hours). Regarding the specific biochemical role ERKI/II plays in synaptic plasticity, the results from the novel taste learning paradigm and from LTP in the CA1 region of the hippocampus suggest that ERKI/II inactivation (Atkins et al., 1998; Berman et al., 1998) produces similar results to the inhibition of protein synthesis (Frey et al., 1988; Rosenblum et al., 1993). Protein synthesis dependency provides biochemically the definition of long-term memory or potentiation: that is, a block of long-term memory and late-phase LTP, leaving short-term memory and early-phase LTP unaffected. ERKI/II is the only member of the MAPK family known to translocate to the nucleus, and by doing so, it is known to modulate gene expression in many cells, including neurons (Impey et al., 1998). However, the immediate effect of the ERKI/II inhibitor on the expression of LTP in vivo (Fig. $1 A$ ) suggests that ERKI/II may also have immediate cytosolic targets, which affect plasticity. It will be of interest to identify the downstream targets of ERKI/II in mature neurons during long- and short-term synaptic modulation (Fig. 6).

\section{REFERENCES}

Acquas E, Wilson C, Fibiger HC (1996) Conditioned and unconditioned stimuli increase frontal cortical and hippocampal acetylcholine release: effects of novelty, habituation, and fear. J Neurosci 16:3089-3096.

Alessi DR, Cuenda A, Cohen P, Dudley DT, Saltiel AR (1995) PD 098059 is a specific inhibitor of the activation of mitogen-activated protein kinase kinase in vitro and in vivo. $\mathrm{J}$ Biol Chem 270:27489-27494.

Andre C, Dos Santos G, Koulakoff A (1994) Cultured neurons from mouse brain reproduce the muscarinic receptor profile of their tissue of origin. Eur J Neurosci 6:1691-1701.

Atkins CM, Selcher JC, Petraitis JJ, Trzaskos JM, Sweatt JD (1998) The MAPK cascade is required for mammalian associative learning. Nat Neurosci 1:602-609.

Auerbach JM, Segal M (1996) Muscarinic receptors mediating depression and long-term potentiation in rat hippocampus. J Physiol (Lond) 492:479-493.

Beninger RJ, Wirsching BA, Jhamandas K, Boegman RJ (1989) Animal studies of brain acetylcholine and memory. Arch Gerontol Geriatr Suppl 1:71-89.
Berman DE, Hazvi S, Rosenblum K, Seger R, Dudai Y (1998) Specific and differential activation of mitogen-activated protein kinase cascades by unfamiliar taste in the insular cortex of the behaving rat. J Neurosci 18:10037-10044.

Bliss TVP, Collingridge GL (1993) A synaptic model of memory: longterm potentiation in the hippocampus. Nature 361:31-39.

Blokland A (1995) Acetylcholine: a neurotransmitter for learning and memory? Brain Res Brain Res Rev 21:285-300.

Blum S, Moore AN, Adams F, Dash PK (1999) A mitogen-activated protein kinase cascade in the CA1/CA2 subfield of the dorsal hippocampus is essential for long-term spatial memory. J Neurosci 19:3535-3544.

Burnette WN (1981) “Western blotting:" electrophoretic transfer of proteins from sodium dodecyl sulfate-polyacrylamide gels to unmodified nitrocellulose and radiographic detection with antibody and radioiodinated protein A Anal Biochem 112:195-203.

Collingridge GL Keal SJ, Mclennan H (1983) Excitatory amino acid in synaptic transmission in the schffer collateral-commissural pathway in the rat hippocampus. J Physiol (Lond) 334:33-46.

Coogan AN, O'Leary DM, O'Connor JJ (1999) P42/44 MAP kinase inhibitor PD98059 attenuates multiple forms of synaptic plasticity in the rat dentate gyrus in vitro. J Neurophysiol 81:103-110.

Crespo P, Xu N, Simonds WF, Gutkind JS (1994) Ras-dependent activation of MAP kinase pathway mediated by G-protein beta gamma subunits. Nature 369:418-420.

Della Rocca GJ, Mukhin YV, Garnovskaya MN, Daaka Y, Clark GJ, Luttrell LM, Lefkowitz RJ, Raymond JR (1999) Serotonin 5-HT1A receptor-mediated Erk activation requires calcium/calmodulindependent receptor endocytosis. J Biol Chem 274:4749-4753.

English JD, Sweatt JD (1997) A requirement for the mitogen-activated protein kinase cascade in hippocampal long term potentiation. J Biol Chem 272:19103-19106.

Eva C, Bovolin P, Balzac F, Botta C, Gamalero SR, Vaccarino FM (1990) Primary cultures of corticostriatal cells from newborn rats: a model to study muscarinic receptor subtypes regulation and function. J Mol Neurosci 2:143-153.

Felder CC (1995) Muscarinic acetylcholine receptors: signal transduction through multiple effectors. FASEB J 9:619-625.

Frey U, Krug M, Reymann KG, Matthies H (1988) Anisomycin, an inhibitor of protein synthesis, blocks late phases of LTP phenomena in the hippocampal CA1 region in vitro. Brain Res 452:57-65.

Fukunaga K, Miyamoto E (1998) Role of MAP kinase in neurons. Mol Neurobiol 16:79-95.

Grant SG, O’Dell TJ, Karl KA, Stein PL, Soriano P, Kandel ER (1992) Impaired long-term potentiation, spatial learning, and hippocampal development in fyn mutant mice. Science 258:1903-1910.

Gutkind JS (1998) The pathways connecting G protein-coupled receptors to the nucleus through divergent mitogen-activated protein kinase cascades. J Biol Chem 273:1839-1842.

Hawes BE, van Biesen T, Koch WJ, Luttrell LM, Lefkowitz RJ (1995) Distinct pathways of Gi- and Gq-mediated mitogen-activated protein kinase activation. J Biol Chem 270:17148-17153.

Impey S, Obrietan K, Wong ST, Poser S, Yano S, Wayman G, Deloulme JC, Chan G, Storm DR (1998) Cross talk between ERK and PKA is required for $\mathrm{Ca}^{2+}$ stimulation of CREB-dependent transcription and ERK nuclear translocation. Neuron 21:869-883.

Jerusalinsky D, Kornisiuk E, Izquierdo I (1997) Cholinergic neurotransmission and synaptic plasticity concerning memory processing. Neurochem Res 22:507-515.

Jones MW, French PJ, Bliss TVP, Rosenblum K (1999) Molecular mechanisms of LTP in the insular cortex in vivo. J Neurosci 19: RC361-RC368.

Jones PG, Curtis CAM, Hulme EC (1995) The functional role of the binding site aspartate in muscarinic acetylcholine receptors, probed by site-directed mutagenesis. Eur J Pharmacol 288:251-257.

Koch WJ, Hawes BE, Allen LF, Lefkowitz RJ (1994) Direct evidence that Gi-coupled receptor stimulation of mitogen-activated protein kinase is mediated by $\mathrm{G}$ beta gamma activation of p21ras. Proc Natl Acad Sci USA 91:12706-12710.

Laemmli UK (1970) Cleavage of structural proteins during the assembly of the head of the bacteriophage $\mathrm{T}_{4}$. Nature 227:680-685.

Lopez-Ilasaca M, Gutkind JS, Wetzker R (1998) Phosphoinositide 3-kinase gamma is a mediator of $\mathrm{G}$ beta gamma-dependent Jun kinase activation. J Biol Chem 273:2505-2508. 
Lu B, Figurov A (1997) Role of neurotrophins in synapse development and plasticity. Rev Neurosci 8:1-12.

Malgaroli A, Tsien RW (1992) Glutamate-induced long-term potentiation of the frequency of miniature synaptic currents in cultured hippocampal neurons. Nature 357:134-139.

Marshall CJ (1995) Specificity of receptor tyrosine kinase signaling: transient versus sustained extracellular signal-regulated kinase activation. Cell 80:179-185.

Martin KC, Michael D, Rose JC, Barad M, Casadio A, Zhu HX, Kandel ER (1997) MAP kinase translocates into the nucleus of the presynaptic cell and is required for long-term facilitation in Aplysia. Neuron 18:899-912.

Mesulam MM (1996) The system level organisation of cholinergic innervation in the human cerebral cortex and its alteration in Alzheimer's disease. Prog Brain Res 109:285-297.

Orban PC, Chapman PF, Brambilla R (1999) Is the ras-MAPK signaling necessary for long term memory formation? Trens Neurosci 22:38-44.

Rosenblum K, Meiri N, Dudai Y (1993) Taste memory: the role of protein synthesis in gustatory cortex. Behav Neural Biol 59:49-56.
Rosenblum K, Berman DE, Hazvi S, Dudai Y (1996) Carbachol mimics effects of sensory input on tyrosine phosphorylation in cortex. NeuroReport 7:1401-1404.

Salter MW (1998) Src, $N$-methyl-D-aspartate (NMDA) receptors, and synaptic plasticity. Biochem Pharmacol 56:789-798.

Schagger H, von Jagow G (1987) Tricine-sodium dodecyl sulfatepolyacrylamide gel electrophoresis for the separation of proteins in the range from 1 to $100 \mathrm{kDa}$. Anal Biochem 166:368-379.

Sugden PH, Clerk A (1997) Regulation of the ERK subgroup of MAP kinase cascades through $\mathrm{G}$ protein-coupled receptors. Cell Signal 9:337-351.

Wess J (1993) Molecular basis of muscarinic acetylcholine receptor function. Trends Pharmacol Sci 14:308-313.

Wess J (1996) Molecular biology of muscarinic acetylcholine receptors. Crit Rev Neurobiol 10:69-99.

Xia Z, Dudek H, Miranti CK, Greenberg ME (1996) Calcium influx via the NMDA receptor induces immediate early gene transcription by a MAP kinase/ERK-dependent mechanism. J Neurosci 16:5425-5436. 